\title{
Mitral valve repair: a valuable procedure with good long term results even when performed infrequently
}

Department of Cardiac Surgery, Northern General Hospital, Sheffield G J Cooper G H Smith

Department of Anaesthetics, Northern General Hospital, Sheffield E MW right

Correspondence to Mr G J Cooper, FRCS Department of Cardiac Surgery, Northern Genera Hospital, Herries Road, Sheffield S5 7AU.

Accepted for publication 9 April 1991

\author{
G J Cooper, E M Wright, G H Smith
}

\begin{abstract}
Objective-To assess the results of mitral valve repair in a series with a low frequency of repair despite a policy to conserve the valve whenever possible.

Design-Retrospective review of case notes with clinical and echocardiographic examination of survivors.

Setting-Cardiac surgery unit in a university teaching hospital.

Patients-62 consecutive patients undergoing mitral valve repair by one surgeon between 1979 and 1989.

Interventions-Mitral valve repair according to the criteria and techniques of Carpentier.
\end{abstract}

Main outcome measures-Frequency of repair, operative mortality, actuarial survival, freedom from reoperation and thromboembolism, clinical state, and echocardiographic state.

Results-The 62 patients, median age 58 years (interquartile range 51 to 64 years), represent $14 \%$ ( $70 \%$ confidence interval $12 \%$ to $15 \%$ ) of the 454 mitral valve operations performed in the study period. Operative mortality was $8 \%$ (70\% CI $5 \%$ to $13 \%$ ). Actuarial survival was $62 \%(70 \%$ CI $43 \%$ to $81 \%)$ at nine years. At nine years actuarial freedom from reoperation was $91 \%(70 \%$ CI $79 \%$ to $102 \%$ ) and freedom from thromboembolism $91 \%(70 \%$ CI $80 \%$ to $102 \%)$. At a median follow up of 33 months (interquartile range 21 to 74 months), 38 of 46 survivors had improved functional state. Of 21 patients who underwent echocardiography one had severe mitral regurgitation and one mitral stenosis.

Conclusion-Although compared with other reports of mitral valve repair the prevalence of repair was low in this series the results are comparable and justify a positive approach to repair in all patients undergoing mitral valve surgery even if this can only be achieved in a small proportion of patients.

In the hands of surgeons committed to the procedure mitral valve repair gives excellent results ${ }^{1}$ but many doubt whether a policy to repair rather than replace the mitral valve is justified when only a few of the patients they see are suitable for repair. Despite the limitations imposed by a population with mitral valves which are often diseased beyond conservation, we have pursued a policy of considering repair in all patients having mitral valve surgery. This study reports the results of the first 10 years of this policy.

\section{Patients and methods}

\section{PATIENTS AND FOLLOW UP}

The study period (1 January 1979 to 26 April 1989) was the first 10 years of a policy to consider repair in all patients having mitral valve surgery. For this period all patients having mitral valve surgery, performed by one surgeon in one hospital, were identified from records of operations. For those undergoing repair information was collected by review of the hospital notes. Patients who were still alive were reviewed in the outpatient clinic and further information was obtained from a history and.clinical examination. All survivors were also invited to undergo echocardiographic examination at a separate visit. Details of those patients who died outside our hospital were acquired from their local hospital or general practitioner or both. Death was considered to be valve related unless there was clear evidence of another cause.

\section{SURGICAL TECHNIQUE}

All procedures were performed through a median sternotomy while the patient was on cardiopulmonary bypass with moderate hypothermia, cold St Thomas' cardioplegia, and topical cold saline.

Mitral valve repair was carried out according to the criteria and techniques described by Carpentier. $^{2}$ A Carpentier-Edwards mitral valve annuloplasty ring was used in all repairs.

The adequacy of the repair was assessed by filling the left ventricle with saline injected through the valve and also by putting a finger in the left atrium while the heart was supporting the circulation. This was then confirmed by monitoring the left atrial pressure trace while the patient was coming off bypass and for the first 24 hours after operation.

\section{ANTICOAGULATION}

All patients were anticoagulated with warfarin for three months; this treatment was continued indefinitely if the patient had atrial fibrillation.

\section{STATISTICAL ANALYSIS}

Continuous variables are presented as median values with the interquartile range. Propor- 
Table 1 Preoperative characteristics of 62 patients (median age 58, interquartile range 51-64) undergoing mitral valve repair 1979-1989

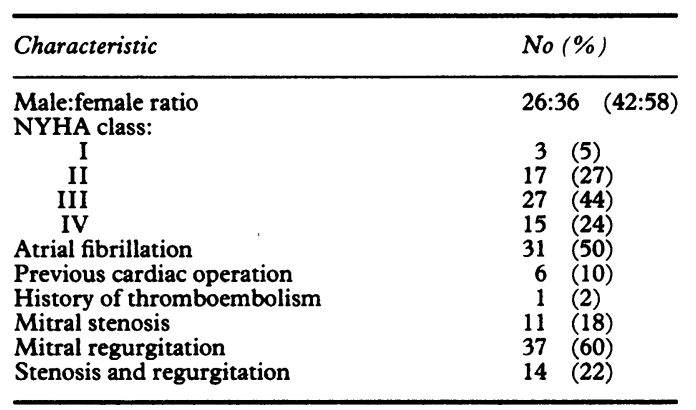

NYHA, New York Heart Association.

Table 2 Aetiology of mitral valve disease in 62 patients undergoing mitral valve repair 1979-1989

\begin{tabular}{lc}
\hline Aetiology & No $(\%)$ \\
\hline Rheumatic & $26(42)$ \\
Degenerative & $26(42)$ \\
Post endocarditis & $6(10)$ \\
Ischaemic & $4 \quad(6)$ \\
\hline
\end{tabular}

tions are given with $70 \%$ confidence intervals $(70 \%$ CI $)$ where appropriate. Comparisons between the first and second halves of the series for operative mortality and the proportion of patients undergoing repair were made by Fisher's exact test and the $\chi^{2}$ test respectively. Actuarial survival, freedom from reoperation, and freedom from thromboembolism were calculated by the method of Kaplan and Meier and the results were given with $70 \%$ confidence intervals.

\section{Results}

PATIENTS

During the study period a total of 454 mitral valve operations were performed; of these 62 $(14 \%, 70 \%$ CI $12 \%$ to $15 \%)$ were repairs. Table 1 shows the details of these patients. We were able to trace all patients and follow up is therefore complete at a median of 36 months (interquartile range 24 to 110 months).

NATURE OF THE VALVE DISEASE AND OPERATIONS PERFORMED

Table 2 shows the aetiology of the mitral valve disease and table 3 the nature of the valve lesions, classified by the functional approach of Carpentier ${ }^{2}$ and by anatomical defect. Tables 4 , 5 , and 6 show the types of repair, the ring sizes used, and the associated cardiac procedures respectively.

Table 3 Functional and anatomical classification of valve lesions in 62 patients undergoing mitral valve repair 1979-1989

\begin{tabular}{|c|c|c|c|c|}
\hline $\begin{array}{l}\text { Functional } \\
\text { classification }\end{array}$ & $\begin{array}{l}\text { Number } \\
\text { (\% of total) }\end{array}$ & Anatomical lesion & $\underset{(\%)}{N u}$ & $\begin{array}{l}\text { nber } \\
\text { of total) }\end{array}$ \\
\hline I & $13(21)$ & $\begin{array}{l}\text { Dilated annulus } \\
\text { Perforated leaflet }\end{array}$ & $\begin{array}{r}10 \\
3\end{array}$ & $\begin{array}{l}(16) \\
(5)\end{array}$ \\
\hline II & 23 (37) & $\begin{array}{l}\text { Ruptured chordae } \\
\text { Elongated chordae }\end{array}$ & $\begin{array}{r}16 \\
7\end{array}$ & $\begin{array}{l}(26) \\
(11)\end{array}$ \\
\hline III & $26 \quad(42)$ & $\begin{array}{l}\text { Commissural fusion } \\
\text { With fused chordae }\end{array}$ & $\begin{array}{r}17 \\
9\end{array}$ & $\begin{array}{l}(27) \\
(15)\end{array}$ \\
\hline
\end{tabular}

Table 4 Repairs performed in 62 patients undergoing mitral valve repair 1979-1989

\begin{tabular}{lll}
\hline Procedure & Number & \% of total \\
\hline Ring and open valvotomy & 20 & 32 \\
Ring and quadrangular resection & 13 & 21 \\
Ring only & 10 & 16 \\
Ring and chordal shortening & 7 & 11 \\
Ring and repair leaflet perforation & 3 & 5 \\
Ring and chordal transposition & 3 & 5 \\
Ring and chordal fenestration & 3 & 5 \\
Ring, open valvotomy, and chordal & 2 & 3 \\
$\quad$ fenestration & 1 & 2 \\
Ring and chordal resection & 1 & \\
\hline
\end{tabular}

FREQUENCY OF REPAIR

During the course of the study an increasing proportion of valves were repaired. In the first five years $8 \%(70 \% \mathrm{CI} 6 \%$ to $10 \%)$ of valves were repaired. In the second five years from 1 January 1984 to 26 April $1989,22 \%$ (70\% CI $18 \%$ to $25 \%)$ of valves were repaired $\left(\chi^{2} 16 \cdot 8\right.$, $\mathrm{p}<0.001)$.

\section{OPERATIVE MORTALITY}

Five patients died within 30 days of operation. There were no in-hospital deaths beyond 30 days, giving an operative mortality of $8 \%(70 \%$ CI $5 \%$ to $13 \%$ ). Table 7 shows the causes of death. Three of the deaths occurred in the first two years of the series. Operative mortality for the first half of the series was $14 \%(70 \% \mathrm{CI} 6 \%$ to $23 \%)$ and for the second $5 \%(70 \%$ CI $2 \%$ to $10 \%$ ) (Fisher's exact test $p=0 \cdot 24)$. Those who died had a median age of 60 years.

\section{LATE MORTALITY}

There were six late deaths. Only two of these were valve related. The actuarial survival, including operative deaths, is $90 \%(70 \% \mathrm{CI}$ $86 \%$ to $95 \%)$ at one year, $79 \%(70 \% \mathrm{CI} 68 \%$ to $89 \%)$ at five years, and $62 \%(70 \%$ CI $43 \%$ to $81 \%$ ) at nine years (fig 1 ).

\section{REOPERATION}

Five patients, all with rheumatic mitral valve disease, required reoperation.

One patient suddenly developed mitral regurgitation 27 days after an initially satisfactory repair. At emergency reoperation the prosthetic ring was found to be partially detached from the annulus. Four further

Table 5 Carpentier-Edwards mitral annuloplasty ring sizes used in 62 patients undergoing mitral valve repair 1979-1989

\begin{tabular}{|c|c|c|}
\hline Ring size ( $\mathrm{mm}$ ) & \multicolumn{2}{|c|}{ Number (\%) } \\
\hline $\begin{array}{l}26 \\
28 \\
30 \\
32 \\
34 \\
36\end{array}$ & $\begin{array}{r}2 \\
11 \\
22 \\
19 \\
6 \\
2\end{array}$ & $\begin{array}{l}(3) \\
(18) \\
(35) \\
(31) \\
(10) \\
(3)\end{array}$ \\
\hline
\end{tabular}

Table 6 Associated procedures performed in 62 patients undergoing mitral valve repair 1979-1989

\begin{tabular}{lrl}
\hline Associated procedures & Number (\% of total) \\
\hline Aortic valve replacement & 10 & $(16)$ \\
Coronary artery bypass & 6 & $(10)$ \\
Close atrial septal defect & 1 & $(2)$ \\
Total & 17 & $(28)$ \\
\hline
\end{tabular}


Table 7 Details of operative deaths in 62 patients undergoing mitral valve repair 1979-1989

\begin{tabular}{|c|c|c|c|c|}
\hline Age (yr) & $\begin{array}{l}\text { Days } \\
\text { post-op }\end{array}$ & $\begin{array}{l}\text { NYHA class } \\
\text { pre-op }\end{array}$ & $\begin{array}{l}\text { Associated } \\
\text { procedures }\end{array}$ & Cause of death \\
\hline $\begin{array}{l}74 \\
63 \\
60 \\
55 \\
36\end{array}$ & $\begin{array}{r}24 \\
6 \\
12 \\
1 \\
7\end{array}$ & $\begin{array}{l}\text { III } \\
\text { III } \\
\text { II } \\
\text { IV } \\
\text { III }\end{array}$ & CABG & $\begin{array}{l}\text { Septicaemia } \\
\text { Myocardial failure } \\
\text { Haemorrhagic pancreatitis } \\
\text { Myocardial failure } \\
\text { Ventricular fibrillation }\end{array}$ \\
\hline
\end{tabular}

AVR, aortic valve replacement; CABG, coronary artery bypass grafting; NYHA, New York Heart Association.

patients have needed reoperation because of mitral regurgitation. In two, there was prolapse of the anterior cusp associated with elongated chordae which had not been recognised at the time of repair. Both these patients had a systolic murmur noted in the immediate postoperative period. All reoperations were needed within two years of repair.

A prosthetic valve was inserted in all patients requiring reoperation; there was no associated mortality.

The actuarial freedom from reoperation is $91 \%(70 \%$ CI $79 \%$ to $102 \%)$ at nine years (fig 2).

\section{THROMBOEMBOLISM}

There were six thromboembolic events in five patients. Three were major and three minor; none was lethal.

The three major thromboembolic events occurred in two patients. One developed sudden loss of consciousness and fixed dilated pupils on the second postoperative day. Consciousness was regained but the patient was left with hemiplegia. The second patient developed hemiplegia five months postoperatively. He was not taking warfarin. This drug was therefore started; but despite adequate anticoagulation he suffered a further stroke five years later.

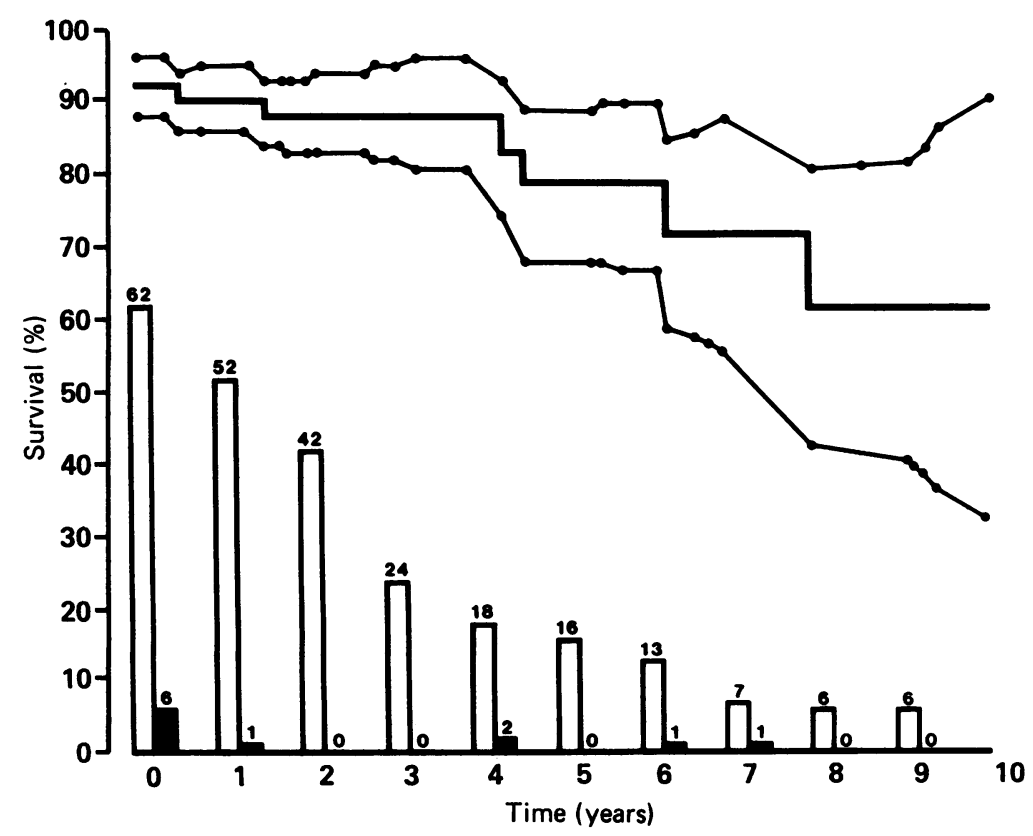

Figure 1 Actuarial survival of 62 patients undergoing mitral valve repair 1979-1989. Outer curves show $70 \%$ confidence interval, open columns show number of patients at risk at the beginning of each year, and solid columns show number of patients dying during that year.
The minor events were episodes of amaurosis fugax, dysphasia, and a monoplegia. All were transient. The patient who developed dysphasia had suffered right hemiplegia after his cardiac catheterisation.

The actuarial freedom from thromboembolism at nine years was $91 \%(70 \%$ CI $80 \%$ to $102 \%$ ) (fig 3).

\section{ENDOCARDITIS}

No patient developed endocarditis postoperatively.

\section{CLINICAL STATE}

After exclusion of those patients who have died or required reoperation 46 remain. Figure 4 shows the preoperative and postoperative functional state of these patients at a median follow up of 33 months (interquartile range 21 to 74 months).

Twenty seven patients have atrial fibrillation and all are taking warfarin. A soft systolic mitral murmur is present in 11 patients but in only one patient is this thought to represent important mitral regurgitation. This patient has a reasonable functional result at present though he may require further mitral valve surgery.

\section{ECHOCARDIOGRAPHY}

Twenty one of the 46 survivors had postoperative Doppler echocardiography; two of these were by the transoesophageal route and the remainder by conventional precordial examination. These examinations were performed at a median of 32 months (interquartile range 12 to 54 months) after operation. In eight (38\%, $70 \%$ CI $26 \%$ to $49 \%$ ) echocardiography showed no regurgitation, in $12(57 \%, 70 \% \mathrm{CI}$ $43 \%$ to $68 \%$ ) there was mild mitral regurgitation, and one $(5 \%, 70 \%$ CI $1 \%$ to $13 \%)$ has severe regurgitation. This is the same patient who has clinical evidence of mitral regurgitation. One patient who had an open mitral valvotomy, chordal fenestration, and insertion of a $32 \mathrm{~mm}$ ring, for rheumatic mitral valve disease, has evidence of mitral stenosis with a calculated valve area of $1.25 \mathrm{~cm}^{2}$ on transoesophageal echocardiography.

\section{Discussion}

The attitude of the surgeon affects the proportion of mitral valves that are judged to be suitable for repair. ${ }^{34}$ Despite a wish to repair the mitral valve whenever possible, we have managed this in only $14 \%$ of patients. This reflects the nature of the mitral valve disease that we see. Most mitral valve disease in this region is post-inflammatory; many valves are calcified with extensive fibrosis of the cusps and shortening of the subvalvar apparatus, which makes repair impossible. During the course of this study we repaired a greater proportion of valves. We attribute this rise to our increasing experience and changes in referral practice from cardiologists. Detailed comparison of these results with those of others with a higher frequency of repair is difficult because of the 


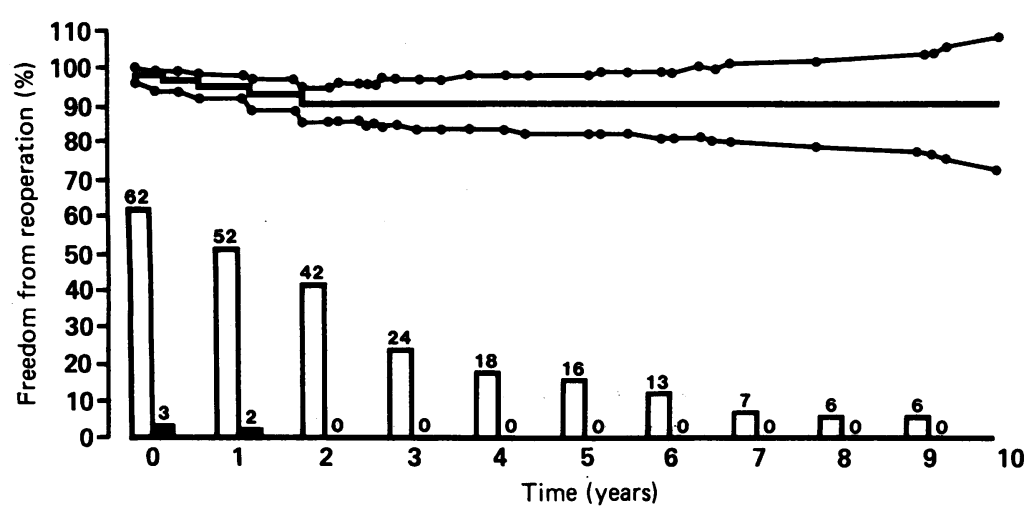

Figure 2 Actuarial freedom from reoperation of 62 patients undergoing mitral valve repair 1979-1989. Outer curves show 70\% confidence interval, open columns show number of patients at risk at the beginning of each year, and solid columns show number of patients undergoing reoperation during that year.

differing patient populations reported but some broad comparisons may be made.

Our operative mortality is higher than that of recently reported series (table 8 ). Three of our deaths occurred during the first two years in which repair was used. Although the decrease in operative mortality to $5 \%$ in the second half of the series was not statistically significant our clinical impression is that this represents a "learning curve", an experience that has been reported by other surgeons. ${ }^{10}$

The variability of long term survival rates between reported series mainly reflects differing prevalences of risk factors in the patients studied. ${ }^{4}$ This report includes "all comers" and thus represents a heterogeneous group of patients of which almost a third underwent a concomitant cardiac procedure. The long term survival, however, is similar to that of other series, some of which contain selected patients (table 8).

All reoperations became necessary within two years of repair. One was due to a technical error that caused separation of the ring. Two of the other four patients who required reoperation had early evidence of residual regurgitation and thus are examples of inadequate repair rather than failure of an initially adequate repair. The intraoperative methods used to assess the competence of repair were those in common use at the time. It is now increasingly

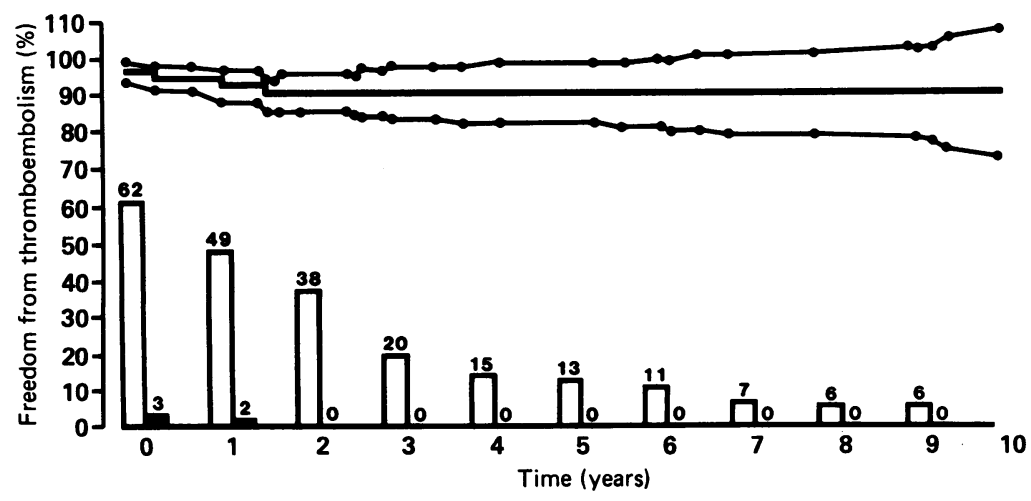

Figure 3 Actuarial freedom from thromboembolism of 62 patients undergoing mitral valve repair 1979-1989. Outer curves show 70\% confidence interval, open columns show number of patients at risk at the beginning of each year, and solid columns show number of patients suffering thromboembolism during that year. recognised, however, that these have their limitations. The measurement of $\mathrm{V}$ waves in the left atrial pressure trace does not correlate with the presence or degree of mitral regurgitation assessed by left ventricular angiography ${ }^{11}$ or by intraoperative epicardial echocardiography. ${ }^{12}$ Filling the left ventricle with saline to test the competence of a valve repair has a false positive rate of $25 \%$ and false negative rate of $33 \%$ compared with epicardial echocardiography. ${ }^{12}$ That these methods of assessing competence at operation are unsatisfactory is borne out by the results in this series. Two of five patients who required reoperation had residual mitral regurgitation that was not recognised at the time of operation. The use of echocardiographic techniques may improve this assessment. Epicardial and transoesophageal echocardiography were of similar sensitivity and specificity ${ }^{13}$ and better than traditional methods. ${ }^{1415}$

The cause of the mitral valve disease in all those requiring reoperation was rheumatic. Galloway et al found that repair was more durable in patients with degenerative disease than with rheumatic disease $e^{9}$ and this accorded with Carpentier's experience. ${ }^{13}$ Operating on patients with rheumatic valve disease Antunes et al found that $10.4 \%$ of their patients required reoperation within 2.6 years ${ }^{5}$ while Cosgrove et al found that in a population with predominantly degenerative disease only $2 \cdot 6 \%$ needed reoperation within 13.5 months. ${ }^{7}$

The low rates of thromboembolism, absence of endocarditis, and excellent functional results, confirmed by echocardiography, match those of the previously cited reports.

Retrospective comparisons of mitral valve

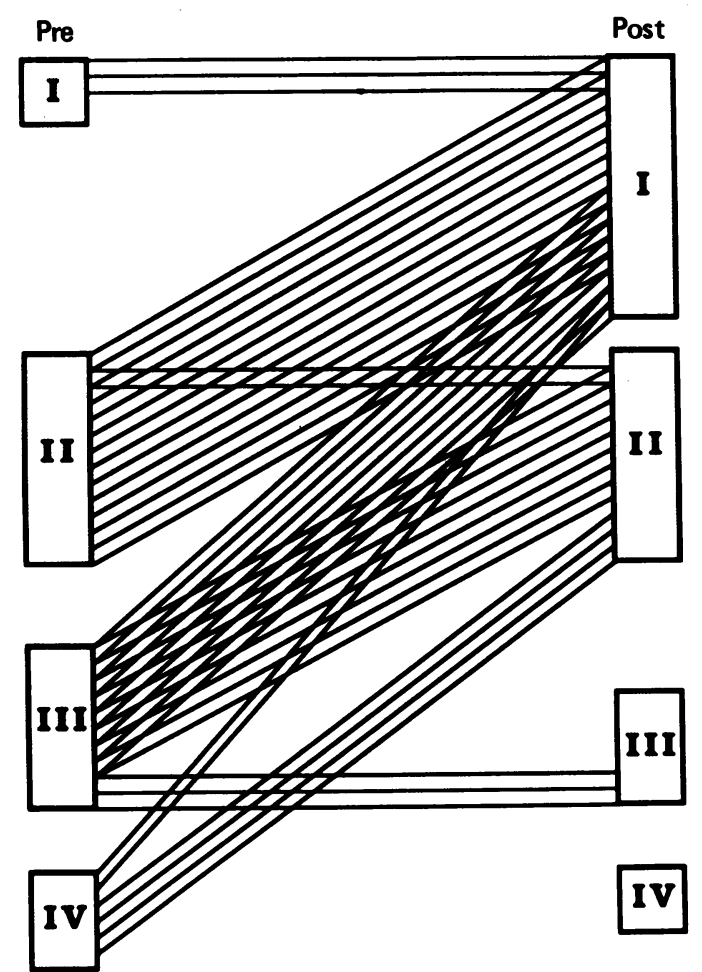

Figure 4 Preoperative and postoperative New York Heart Association class of 46 patients undergoing mitral valve repair 1979-1989 at a median follow up of 33 months. 
Table 8 Recent results of mitral valve repair

\begin{tabular}{|c|c|c|c|c|c|c|}
\hline Author & $\begin{array}{l}\text { Mean age } \\
\text { of series (yr) }\end{array}$ & $\begin{array}{l}\text { Frequency } \\
\text { of repair }(\%)\end{array}$ & $\begin{array}{l}\text { Nature of } \\
\text { valve disease }\end{array}$ & $\begin{array}{l}\text { Operative } \\
\text { mortality }(\%)\end{array}$ & $\begin{array}{l}\text { Actuarial } \\
\text { survival }(\%)(y r)^{\star}\end{array}$ & $\begin{array}{l}\text { Freedom from } \\
\text { reoperation }(\%)(y r)^{\star}\end{array}$ \\
\hline $\begin{array}{l}\text { Antunes et al } \\
\text { Cohn } e t a l^{5} \\
\text { Cosgrove et al } \\
\text { Deloche et al } \\
\text { Eguaras et } a l^{1} \\
\text { Galloway et al } \\
\text { Sand et } a l^{4}\end{array}$ & $\begin{array}{l}22 \\
61 \\
60 \\
49 \\
45 \\
51 \\
53\end{array}$ & $\begin{array}{l}36 \\
30\end{array}$ & $\begin{array}{l}\text { Mixed, Rh } \\
\text { Reg, Deg } \\
\text { Reg, Deg } \\
\text { Reg, mixed } \\
\text { St, Rh } \\
\text { Mixed, mixed } \\
\text { Reg, mixed }\end{array}$ & $\begin{array}{l}1.9 \\
1.6 \\
4 \cdot 3 \\
5 \cdot 3 \\
1 \cdot 4 \\
5 \cdot 4 \\
5\end{array}$ & $\begin{array}{l}90(4) \\
84(4) \\
90(2) \\
73(15) \\
98(8) \\
90(5) \\
76(5)\end{array}$ & $\begin{array}{l}78(4) \\
85(4) \\
96(2) \\
87(15) \\
93(8) \\
84(5) \\
74(8)\end{array}$ \\
\hline
\end{tabular}

Nature of valve disease: stenosed (St), regurgitant $(\mathrm{Reg})$, or a combination of the two (mixed), followed by the aetiology of the valve disease $(\mathrm{Rh}=\mathrm{rheumatic}, \mathrm{Deg}$

$=$ degenerative, mixed = various)

* Number of postoperative years at which actuarial survival and freedom from reoperation were calculated.

repair with replacement have shown significantly less valve related morbidity with repair. $^{416}$ In addition, preservation of the mitral valve apparatus improved postoperative left ventricular function. ${ }^{17} 18$ This accumulating evidence of benefit and the reported safety of mitral valve repair led to the adoption of a positive approach to reparative surgery during the 10 years of this study.

With increasing experience we have repaired more valves but because we have adhered to the principle of applying reproducible techniques this has not been at the expense of satisfactory clinical results. Echocardiographic methods of intraoperative assessment should lead to further improvements. Carpentier estimated that far more mitral valves are repairable than we have found suitable, ${ }^{1}$ even in the latter half of the series. Nevertheless, we believe that the results obtained in our patients are comparable with those of others and that repair merits consideration in all patients undergoing mitral valve surgery even if it can be achieved in only a small proportion of patients.

We thank Dr A E Proctor and Dr D R Naik for carrying out the

postoperative echocardiography. care, Edwards CVS Division.

1 Deloche A, Jebara VA, Relland JYM, et al. Valve repair with Carpentier techniques. The second decade. J Thorac Cardiovasc Surg 1990;99:990-1002.

Carpentier A Cardiac valve surgery - the "French correction". J Thorac Cardiovasc Surg 1983;86:323-37.

3 Carpentier A, Chauvaud S, Fabiani JN, et al. Reconstructive surgery of mitral valve incompetence. Ten year appraisal. surgery of mitral valve incompetence. Ten

4 Sand ME, Naftel DC, Blackstone EH, Kirklin JW, Karp
RB. A comparison of repair and replacement for mitral valve incompetence. $J$ Thorac Cardiovasc Surg 1987; 94:208-19.

5 Antunes MJ, Magalhaes MP, Colsen PR, Kinsley RH. Valvuloplasty for rheumatic mitral valve disease. A surgical challenge. J Thorac Cardiovasc Surg 1987;94:44-56. 6 Cohn LH, DiSesa VJ, Couper GS, Peigh PS, Kowalker W, Collins JJ. Mitral valve repair for myxomatous degeneration and prolapse of the mitral valve. $J$ Thorac Cardiovasc Surg 1989;98:987-93.

7 Cosgrove DM, Chavez AM, Lytle BW, et al. Results of mitral valve reconstruction. Circulation 1986;74(suppl I):I-82-7.

8 Eguaras MG, Luque I, Montero A, et al. Conservative operation for mitral stenosis. J Thorac Cardiovasc Surg operation for mit

9 Galloway AC, Colvin SB, Baumann FG, et al. Long-term results of mitral valve reconstruction with Carpentier techniques in 148 patients with mitral insufficiency. Circulation 1988;78(suppl I):I-97-105.

10 Antunes MJ, Colsen PR, Kinsley PH. Mitral valvuloplasty: a learning curve. Circulation 1983;68(suppl II):II-70-5.

11 Fuchs RM, Heuser RR, Yin FCP, Brinker JA. Limitation of pulmonary wedge $V$ waves in diagnosing mitral regurgitation. Am J Cardiol 1982;49:849-54.

12 Czer LSC, Maurer G, DeRobertis M, et al. Intra-operative evaluation of mitral regurgitation: superiority of doppler color flow mapping [abstract]. Circulation 1986;74(suppl II):II-394.

13 Kleinman JP, Czer LSC, DeRobertis M, Chaux A, Maurer G. A quantative comparison of transesophageal and epicardial color doppler echocardiography in the intraoperative assessment of mitral regurgitation. $A m J$ intraoperative assessment

14 Maurer G, Czer LSC, Chaux A, et al. Intraoperative Doppler color flow mapping for assessment of valve repair Doppler color flow mapping for assessment of valve repair

15 Kyo S, Takamoto S, Matsumura M, et al. Immediate and early postoperative evaluation of results of cardiac surgery by transesophageal two dimensional Doppler echocardiography. Circulation 1987;76(suppl V):V-113-21.

16 Galloway AC, Colvin SB, Baumann FG, et al. A comparison of mitral valve reconstruction with mitral valve replacement: intermediate term results. Ann Thorac Surg 1989;47:655-62.

17 Bonchek LI, Olinger GN, Siegel R, Tresch DD, Keelan $\mathrm{MH}$. Left ventricular performance after mitral reconstruction for mitral regurgitation. $J$ Thorac Cardiovasc Surg 1984;88:122-7.

18 Hansen DE, Sarris GE, Niczyporuk MA, Derby GC, Cahill PD, Miller DC. Physiologic role of the mitral apparatus in left ventricular regional mechanics, contraction synergy and global systolic performance. J Thorac Cardiovasc Surg 1989;97:521-33. 